\title{
Informal Female Care Givers of Older Adults with Dementia in Taiwan
}

\author{
Chiung-Yu Huang \\ MeiHo Institute of Technology, Taiwan
}

\begin{abstract}
Family care givers providing a major portion of care giving often experience stress related to the negative consequences for their health. Female care givers often more heavily involved care giving activities than males. Care givers' gender studies have seldom conducted in Taiwan. The purpose of this study was to explore the relationship of demographic factors and coping on health of female care givers of older adults with dementia in Taiwan. In addition, whether coping mediated or moderated the relationship between stress and care giver's health was also examined. Lazarus and Folkman's Stress model guided this study. Using a secondary data analysis method, this study examined data collected from the family care givers of older adults with dementia (2002). One hundred and three female care givers were analyzed by applying Pearson correlation, simple and multiple regression analysis. The findings showed care givers who are younger, more income, and with helpers had better health. Care givers who had less income, without helpers, and caring for care recipients with more behavioral problems had more depressive symptoms. In addition, mediating effect of avoidance coping was supported in this study. The data analysis from this study will provide a basis for nurses to develop interventions that minimize the negative impacts on female care givers.
\end{abstract}

(C) 2004 Californian Journal of Health Promotion. All rights reserved.

Keywords: dementia, Taiwan, care givers, elderly

\section{Introduction}

Dementia is a serious disease and usually has a progressively deteriorated outcome. Mostly, providing care for these dementia patients is their families, which may cause negative consequences of health. Providing care for impaired older adults is often stressful, the chronic stress of caring for a dementia patient has a significant effect on care giver's health (Brody, 1985; Wright, Hickey, Buckwalter, Hendrix, \& Kelechi, 1999).

The prevalence rate of dementia is increasing among the aged population. Approximately 5$8 \%$ of older adults aged 65 and above, $15-20 \%$ of persons over aged 75 , and $25-50 \%$ of persons over age 85 year may have dementia in the US (Schindler \& Cucio, 2000).

In Taiwan, the dementia prevalence rate was 35\% in 1995 (Department of Health Executive Yuan). Of those, $70-80 \%$ of the dementia patients were cared for by their families, $8.4 \%$ cared for by nursing professional, and $13.7 \%$ institutionalized in nursing homes (Department of Health Executive Yuan, 1995). Dementia illness course is unpredictable, and rapidly declines. The survival time after senile dementia of the Alzheimer's type onset may range from eight to twenty years. Most family care givers choosing to provide community-based care to the elderly often experience stress-related health problems because of the long duration of caring, an overload of responsibilities, and role conflicts (Sayles-Cross, 1993).

In the US, women, including wives, daughters, and daughters-in-law, comprise the largest group of care givers to elders (Stone et al., 1987). In addition, there is a gender-based division of labor where males and females play different roles of assistance. Women provide most care giving, whereas men are more likely to make the service arrangements, do home repairs, or provide intermittent assistance (Montgomery \& Borgatta, 1989). Moreover, elderly wives may 
be at great risk for stress and depression because they experience role regression and role entrenchment, in which spouses forgo their social and familial roles and focus completely on caring for their spouses (Given, Collins, \& Given, 1988). Furthermore, female family care givers have higher levels of anxiety than male care givers (Huang, 2003; Walker, Martin, \& Jone, 1992). It may be that female care givers are more involved or take more responsibilities than male care givers.

In Taiwan, most family care givers are also female. Taiwan's females have multiple roles during care giving. The overload responsibilities of the care givers may cause higher stress. Additionally, female informal care givers may experience social inequality and lack of social sources. Thus, female care givers are often greater suffering health problems than males (Anderson et al., 1995; Pruchno \& Potashnik, 1989).

\section{Purpose}

The purpose of this study is to explore the impact of coping and the influence of demographic characteristics of care giving stress on health of female care givers of older adults with dementia. Care giving has been identified as very stressful; consequently one aim is to describe the relationships among stress, coping, and depressive symptoms of female care givers. Moreover, coping is also examined whether mediated or moderated the relationship between care giving stress and health of female care givers. Little research has investigated the effects of coping on health of female dementia care givers. Research questions are stated as follows:

1. What are the relationships between age, income, duration, helper, behavioral problems, coping, and health?

2. What are the influences of age, income, duration, helpers, and care recipient's behavioral problems on care giver's health?

3. What are the effects of coping on care giver's health?

4. Is the relationship between care giving stress and health moderated by coping?

5. Is the relationship between care giving stress and health mediated by coping?

\section{$\underline{\text { Context of Care giver Stress } \quad \underline{\text { Intervening Variables }} \text { Outcomes }}$}

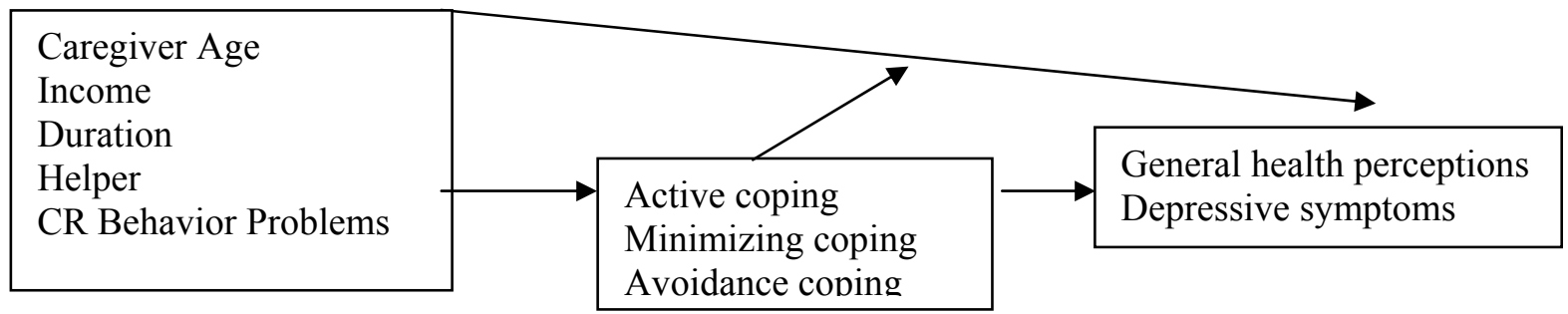

Figure 1

Adapted from Lazarus and Folkman's (1984) Stress and Coping Model

\section{Background}

Many studies have indicated that long-term stressful care giving negatively affects care givers' mental and physical health. Thus, the deterioration of health of care givers usually results in the institutionalization of care recipients (Brown, Poter, \& Foster, 1990). Crassel (1995) indicated family care givers had significantly higher somatic symptoms and perceived burden. Also, Gonzalez-Salvador et al. (1999) implied that the stress of family care givers of Alzheimer's patients was strongly 
related to psychosocial and physical morbidity of care givers. Female care givers comprised approximately $70-80 \%$ of the care giving population and thus female care givers reported higher levels of physical and mental health problems than males (Borden \& Berlin, 1990; Yee \& Schultz, 2000).

Coping has been defined as "constantly changing cognitive and behavioral efforts to manage specific external and/or internal demands that are appraised as taxing or exceeding the resources of the person" (Lazarus \& Folkman, 1984, p. 141). A variety of characteristics may influence coping abilities, such as family relationships, care giving duration, age, gender, and income (Brody, 1981). Pearlin et al. (1989) suggested that the nature of the stressor encountered in a situation influences how the person copes with his/her situation. Coping behaviors that people use to manage situations may involve individual efforts to meet the demands of care giving or to make them more manageable. Smyth and Yarandi (1996) analyzed the factor structure of the Ways of Coping Questionnaire (Lazarus \& Folkman, 1984) and defined three coping strategies: active, avoidance, and minimizing the situation. Active coping involves aggressive efforts to change situations; avoidance coping involves wishful thinking and efforts to escape problem situations; and minimizing the situation reflects on attempt to remove oneself from an unpleasant situation (Musil \& Ahmad, 2002; Smyth \& Yarandi, 1996). These three coping strategies are often used as the interventions for helping care givers to adapt to their care giving stress. Thoits (1994) used panel data to explore the effects of problem solving (active coping) on the psychological health outcomes of informal care givers and suggested that individuals may use active coping to minimize their difficulties.

This study was a model-based, cross-sectional study that used a descriptive correlational design to examine the relationships among demographic factors, situational factors, and coping on health outcomes of family care givers of older adults with dementia in Taiwan. One hundred and three female care givers which was a secondary data from 148 primary family care givers of older adults with dementia in Huang and Musil's study (2003). Lazarus and Folkman's (1984) Stress and Coping model guided this study and was used to test the proposed relationships among the study variables. Mediating and moderating effects of coping were also examined.

\section{Health in Care givers}

Depressive symptoms are often the consequence of care giving stress (Schulz et al., 1995; Schulz, Newsom, Mittelmark, Burton, Hirsch, \& Jackson, 1997; Wright, Hickey, Buckwalter, Hendriex, \& Kelechi, 1999). Whitlatch and colleague (1997) investigated the predictors of depression in 202 family care givers of cognitively impaired adults and found that the majority of care givers had great depressive symptoms as measured by using the CES-D depression scale. Their CES-D scores were between 19.71 and 20.82 throughout the oneyear study period. The mean rates of the three waves of data: baseline $=20.8$, time $2=20.5$, and time $3=19.7$ were more than twice as high as studies of the general adult population (with mean CES-D scores ranged from 8.6 to 9.9) (Linn, Dean, \& Ensel, 1986).

Stone, Cafferata, \& Sangl (1987) found that after care givers' physical health tend to decline after beginning care giving. Because elderly persons with dementia have cognitive and behavioral impairments, care givers may feel exhausted in providing care for them. Kiecolt-Glaser, Dura, Speicher, Trask, and Glaser (1991) reported that the care giving stress has a negative influence on care givers' immune systems. Kiecolt-Glaser et al. (1991) examined 69 spousal care givers who had already taken care of the elderly with dementia for an average of five years and 69 non-care givers. After 13 months follow-up, care givers showed decrements compared to non-care givers on three measures of cellular immunity.

\section{Study Variables of Conceptual Framework Age}

Age is often associated with health outcomes of care givers. Sparks, Donner, \& Keane-Hagerty (1998) indicated care giver's age predicted poorer physical health for both wives and husbands. Younger care givers experienced 
more depressive symptoms or burden than older care givers (Anderson et al., 1995; Lawton, Rajagopal, Brody, \& Kleban, 1992; Parks \& Pilisuk, 1991).

\section{Incomes}

Income may influence a care giver's health. Families may receive financial benefit from the government when taking care for their family members. Zanetti and his colleagues (1998) indicated that $16.5 \%$ of family care givers reported their household income as insufficient. There is a positive relationship between income and health of dementia care givers (Lawton et al., 1992; Schulz \& Williamson, 1991). Schulz and Williamson (1991) conducted a two-year longitudinal study and greater depression in dementia care givers was related to inadequate income at baseline (time I) and (one year) time III.

\section{Duration}

Care giving duration may have a relationship to the care giver's health outcomes. Kao, Lu, Yen, \& Liu (1999) reported that family care givers providing longer duration of care for their frail elders had experienced fewer burdens than those with a shorter time of care giving. This result may be due to care givers adapting to their situation during the longer care giving duration or the family care givers having access to support resources. Moen, Robinson, and Dempester-McClain (1995) investigated care giving and women's well-being and found a curvilinear relationship between care giving duration and role conflicts. In the beginning, female care givers may disrupt their roles or regular patterns, while over time, the female care givers may go back to their regular life patterns. After a longer period of care giving, the linear relationship between care giving duration and role conflict became a negative relationship.

Additionally, Schultz and Williamson's two-year (4 waves) longitudinal study showed that care givers of care recipients with $\mathrm{AD}$ expressed declines of health and great depressive symptoms (1991). In their study, female care givers maintained high, stable rates of depressive symptomatology during the two-year period, whereas male care givers showed significant increases in depression over time. That is, the longer the duration of care giving, the higher the scores of the depressive symptoms for male care givers. Moreover, Schulz and Williamson indicated that when perceptions of available social support declined, the depression of care givers increased during the baseline (time I) to two years (time IV).

\section{Helper}

In Taiwan, hiring an assistant from foreign countries to help with care giving has been commonly utilized over the last five years. Paidhelpers usually come from Philippines, Malaysia, and Mainland China, and were trained by some private or public agency to provide assistance for chronically ill persons. These helpers often provide direct care, housekeeping, and companionship and may assist with housework or meeting physical needs. About 3$33 \%$ of all informal family care givers have assistants including both Taiwanese and foreign assistants (Hung et al., 1999). Having a paidhelper is significant to care givers' health (Huang, 2003). Only one study supports the benefits of foreign paid helpers for family care givers. The benefits may be similar to in-home respite care, with the exception of formal health services from professionals. Curran (1995) mentioned that the benefits of in-home respite include improved mood, reduced distress, and decreased time consumed in care giving activities (Berry, Zarit, \& Rabatin, 1991; Montgomery, 1995).

\section{Behavioral Problems}

Family care givers often take care of dementia patients who are cognitively or physically dependent for twenty years or more prior to the patient's institutionalization or death (Wright, Clipp, \& George, 1993). Family care givers may use formal health services (e.g., respite care, adult day care center) to supplement their informal support network such as relatives, friends, and neighbors. However, the services are limited and some family care givers may not offer enough for their needs.

Beach, Schulz, Yee, and Jackson (2000) conducted a care giver study to examine the effects of changes in care giving involvement on 
health-related outcomes of care givers who took care of impaired older adults. Beach et al. showed that care giving is associated with generalized stress, which is consistent with the findings of previous studies (Aneshendel et al., 1995; Chiu et al., 1998; Chou et al., 1999; Goode et al., 1998). Moreover, changes in spouse physical-impairment levels were also related to worse health-related outcomes. That is, the greater the severity of physical impairments of the care recipient with dementia, the higher the levels of stress in the care givers. Zanetti, Frisoni, Biancheti, Tamazza, Gigoli, and Trabucchi (1998) reported that poor cognition and high frequency of behavioral disturbance of care recipients with dementia was significantly related to the higher depressive symptoms of family care givers (Gallicchio, Siddiqi, Langenberg, \& Baumgarten, 2002). Consistently, Ory, Hoffman, Yee, Tennstedt, and Schulz (1999) investigated the differences between dementia and non-dementia care givers with regard to care giver well-being and found that dementia care givers spent more time and were more involved in care giving than nondementia care givers. Thus, dementia care givers experienced more negative outcomes than nondementia care givers.

Haley, Levine, Brown, and Bartilucci (1987) reported that care givers' appraisals of the care recipient's behavioral problems as stressful and appraisals of themselves as inadequate to deal with such behaviors, the number of care recipient's behavioral problems were positively related to the depressive symptoms of care giver's. Haley and colleagues (1996) stated care givers who used more problem-coping (active coping) strategies had better health outcomes. There are no clear results about the relationship between the behavioral problems of care recipients and coping used by care givers. Little research has been done to examine the relationship between the health outcomes of care givers and behavioral problems of the elderly with dementia in Taiwan.

\section{Methodology}

Using a secondary data analysis method, this study examined data collected from the family care givers of older adults with dementia (Huang and Musil, 2003). One hundred and three female care givers were from the data-set of Huang's (2003) study. The subjects of primary study in this study were informal female care givers of older adults aged 65 or above who had Alzheimer's disease or another form of dementia. The name lists of family care givers of the older adults with dementia were provided by the Kaohsiung Family Care giver Association and one nursing home in the South of Taiwan. Inclusion criteria for this secondary study consisted of being a primary family care giver who: (1) was female, (2) was able to understand or communicate in Chinese or Taiwanese, (3) had been taking care of an elderly family member with dementia at home for at least 6 months prior to the time of the study, and (4) provided unpaid care for a minimum of five hours weekly.

\section{Sample}

One hundred three females out of 148 primary family care givers lived in the suburban or city areas in the South of Taiwan. They were recruited by the name list provided by a family care giver association and a nursing home. Subjects were interviewed to complete the study questionnaire. The subjects for this study ranged in age from 27 to 82 years $(\mathrm{M}=55.70, \mathrm{SD}=$ 12.07). Table 1 shows the description of individual characteristics of 103 subjects. Care giver duration of care giving, which was counted after the primary care giving began to care for their elderly families with dementia, ranged from 6 to 180 moths $(\mathrm{M}=39.79, \mathrm{SD}=33.85)$. A large portion of family care givers was married $(\mathrm{n}=93,90.3 \%)$. Another variable was monthly household income, which was dichotomized for analytic purposes $(\leq 40,000$ NT dollars and $>$ 40,000 NT dollars); Sixty-nine of care givers had a monthly income of less than 40,000 (67\%) and 34 care givers had incomes greater than 40,000 (33\%). Sixty-one (59.2\%) care givers had paid helpers and $42(40.8 \%)$ did not have paid-helpers. Most subjects were married (90.3\%), un-employed (72.8\%), and spent more than 40 hours weekly $(71.8 \%)$ taking care of their elderly family members (See Table 1). 
Table 1

Descriptive Statistics of Individual Characteristics of Subjects $(\mathrm{N}=103)$

\begin{tabular}{|c|c|c|c|}
\hline Variable & Mean \pm SD & N & \% \\
\hline Age & $55.70 \pm 12.07$ & & \\
\hline Range 27-82 & & & \\
\hline Marital Status & & & \\
\hline Single & & 10 & 9.7 \\
\hline Married & $39.79 \pm 33.85$ & & \\
\hline Duration (Months) & & & \\
\hline Range 6-180 & & & \\
\hline Relationship to Care Recipient & & 37 & 36 \\
\hline Spousal & & 66 & 64 \\
\hline Adult Child & & & \\
\hline Monthly Income (NT dollars)* & & 69 & 67 \\
\hline$<40,000$ & & 34 & 33 \\
\hline$>40,000$ & & & \\
\hline Hours Per Week & & 7 & 6.8 \\
\hline $0-10$ hours & & 9 & 8.7 \\
\hline $11-20$ hours & & 3 & 2.9 \\
\hline $21-30$ hours & & 10 & 9.7 \\
\hline $31-40$ hours & & 74 & 71.8 \\
\hline$>40$ hours & & & \\
\hline Helpers & & 42 & 40.8 \\
\hline No & & 61 & 59.2 \\
\hline Yes & & \\
\hline$* 1$ USD $=35$ NT Dollars & & & \\
\hline
\end{tabular}

\section{Instruments}

The demographic information sheet and four measurements were provided. The Center for Epidemiological Studies-Depression (CES-D) (Radloff, 1977), the General Health Perceptions subscale of the Short Form-36 Health Survey (Ware, 1992) had been used in Taiwan and had acceptable reliability. Behavioral Problems Checklist (BPC; Niederehe, 1988) and modified Ways of Coping (Lazarus \& Folkman, 1984; Smyth \&Yarandi, 1996) had acceptable reliability in Huang's study (2003).

\section{Depressive Symptoms}

Depressive Symptoms were measured by the Center for Epidemiological Studies-Depression Scale (CES-D Scale; Radloff, 1977). The CES$\mathrm{D}$ is a 20-item scale, which was designed for screening depressive symptoms in the general population. Respondents are asked to rate on a 4 -point scale $(0=$ rarely or none of the time, $1=$ some or little of the time, $2=$ occasionally or a moderate amount of time, 3 = most or all of the time) how frequently they had experienced certain symptoms or feelings during the previous week. Scores range from 0 to 60 , with higher scores reflecting greater depressive symptoms. The total score was calculated by adding up by all ratings, with higher scores indicating with more depressive symptoms (Radloff, 1977). Scores on the CES-D Scale at or above 16 are considered at a risk for clinical depression (Radloff, 1977). The CES-D has been translated in Chinese to measure depressive symptoms in an elderly population in Taiwan (Lyu \& Lin, 2000). Lyu and Lin (2000) reported that the average CES-D score of community-dwelling elders in the south of Taiwan was 13.21. The mean of this care giver sample was $26.98(\mathrm{SD}=$ 10.14; range $=2-48$ ). The Cronbach's alpha coefficient for Huang's care giving study was .89 (2003). 


\section{General Health Perceptions}

Physical health was measured with the general health perception scale of the 36-item Short Form (SF-36) of the Medical Outcomes Study questionnaire, which was designed as a generic indicator of health (Mchorney, Ware, \& Reczek, 1993; Ware, 1990; Ware \& Sherborne, 1992). The SF-36, an easy-to-complete questionnaire, has been shown to be a reliable and valid instrument. Due to the brevity of the SF-36, the instrument has been widely used among diverse populations both in the USA and internationally such as German, Spanish, French, Taiwan, Chinese, and Japanese studies (Krongrad et al., 1997; Ware et al., 1995). Only the general health perception scale, a five-item scale, was used in this present study to evaluate the physical health of care givers. The General Health Perceptions subscale appeared to be sensitive to physical health problems (Nerenz et al., 1992). The first item asked individuals to rank their perception of health (excellent $=1$, very good $=2$, good $=$ 3 , fair $=4$, poor $=5$ ). Another four items assessed the degree to which the subject agrees with the questions about their health. The scores were ranked from definitely true $=1$ to definitely false $=5$. Subjects were asked to rank their health including the following four questions: "I am somewhat ill," "my health is excellent," I am as healthy as anybody I know," "I have been feeling bad lately" (definitely true $=1$, mostly true $=2$, not true $=3$, mostly false $=4$, definitely false =5). In Huang's (2003) study, the Cronbach's alpha coefficient of the General Health Perception scale was .90 .

\section{Care Recipient's Behavioral Problems}

Behavioral problems of the care givers were assessed with the Behavioral Problem Checklist (BPC), which was designed to assess the range of behavioral problems that the elderly with dementia living in a private home may present, and the burdens these may cause for family care givers. The BPC was developed at the Texas Research Institute of Mental Sciences (TRIMs) in Houston, which included 52 items of functioning in both the mental health and social role areas (Niederehe \& Fruge, 1984). Care giver's response to the 52 items provided a profile of elderly symptoms, deficits, and interpersonal behaviors; the care giver's emotional reactions to the care recipient's behavioral problems were also included. For this study, the investigator only used the "FREQUENCY" dimension of the scale to examine how often the care recipient demonstrated the behavioral problems during the previous week, which were ranked on a 5-point scale $(0=$ never, $1=$ not in last week, $2=1-2$ times last week, $3=3-6$ times last week, $4=$ daily). Cronbach's alpha for the entire 52-item scale was 0.89. and Cronbach's alpha was .90 in Huang's study (2003).

\section{Coping}

Coping had been defined as cognitive and behavioral attempts to manage events that are appraised as stressful (Lazarus \& Folkman, 1984; Folkman \& Lazarus, 1987) and were measured by the modified Ways of Coping Checklist (M-WOC) (Smyth \& Yarandi, 1996). The modified Ways of Coping Checklist was from a 66-item instrument that was determined to have three factors: active coping (15 items, alpha $=.84)$, avoidance coping (10 items, alpha $=.80$ ), and minimizing the situation (10 items, alpha $=.84)$ in a sample of 656 AfricanAmerican women (Smyth \& Yarandi, 1996). The modified WOC was a 35 -item on a fourpoint Likert-type summative scale $(0=$ does not apply and or not used, $1=$ used somewhat, $2=$ used quite a bit, 3 = used a great deal). Musil and Ahmad (2002) conducted a study related to the health of grandmothers and reported the reliability of active coping, avoidance coping, and minimizing the situation as $.87, .83$, and .81 . In Huang (2003) study, Cronbach's alpha coefficient of active coping, avoidance coping, and minimizing the situation were as $.85, .75$, and .73 , and .85 for 35 items of the M-WOC.

\section{Results}

Descriptive statistics were computed on all study variables and were summarized by frequency, mean, and standard deviations. The distribution for continuous variables was examined and normal. Cronbach's alpha coefficients were obtained for all reliabilities. Pearson's Correlation and multiple regression statistics were used to test all hypotheses. A significant alpha level of .05 was used for all statistical tests. 
The data included descriptive statistical analysis, preliminary data analysis, and hypothesis testing. Pearson product-moment correlation, simple regression, and hierarchical multiple regression were used to analyze the predictors of health outcomes. Preliminary analysis involved examining the data cleaning and testing the assumptions for regression model. After performing the preliminary data analysis, the main data analysis was run by using SPSS version 11.0.

Table 2

Correlations Age, Income, Duration, Helper, and Care Recipient's

Behavioral Problems with Coping, and Health $(\mathrm{N}=103)$

\begin{tabular}{|l|l|l|l|l|l|}
\hline \multicolumn{1}{|c|}{ Variables } & $\begin{array}{c}\text { Active } \\
\text { Coping }\end{array}$ & $\begin{array}{c}\text { Avoidance } \\
\text { Coping }\end{array}$ & $\begin{array}{c}\text { Minimizing } \\
\text { Coping }\end{array}$ & $\begin{array}{l}\text { General Health } \\
\text { Perceptions }\end{array}$ & \multicolumn{1}{c|}{$\begin{array}{c}\text { Depressive } \\
\text { Symptoms }\end{array}$} \\
\hline Age & $-.449^{* *}$ & $-.282^{* *}$ & -.052 & $-.292^{* *}$ & .024 \\
\hline Income & $.294^{* *}$ & .127 & $.194^{*}$ & $.199^{*}$ & $-.334^{* *}$ \\
\hline Duration & .000 & -.148 & .021 & .091 & -.071 \\
\hline Helper & .008 & -.017 & -.066 & .182 & $-.231^{*}$ \\
\hline Behavioral Problems & .130 & $.291^{* *}$ & .104 & -.133 & $.213^{*}$ \\
\hline
\end{tabular}

$p=.05,{ }^{* \prime \prime} p=.01$ (2-tailed)

\section{Relationship Among Variables}

Age. Older care givers had less active coping and less avoidance coping than younger care givers $(r=-.449, p<.01)$ (See Table 2$)$. In addition, there was a negative correlation between age and general health perceptions $(\mathrm{r}=$ $-.292, \mathrm{p}<.01$ ), it indicated older care givers had worse health than younger care givers.

Incomes. There was a significant positive correlation between income and active coping $(\mathrm{r}=.394,<.01)$ and income and minimization coping as well $(\mathrm{r}=.194,<.05)$. The more income the care givers had, the more active coping they used. In addition, there was a significantly positive relationship between income and general health perceptions $(\mathrm{r}=.199$, $\mathrm{p}<.05)$, but negative relationship between income and depressive symptoms $(r=-.334, p$ $<.01)$.

Helper. Care givers who had paid helpers usually had fewer depressive symptoms and healthy than those without the use of paidhelpers. When care recipients have more behavioral problems, care givers have more depressive symptoms and worse general health.

\section{The Effects of Coping}

For the main effect of coping, younger female care givers when they had paid helpers and used less avoidance coping had better health, accounted for $26.4 \%$ in general health perceptions (See Table 3). On the other hand, female care givers with no paid helpers had lower incomes, used more avoidance coping, and had more depressive symptoms (See Table 4).

For the mediating effect of coping, avoidance coping was a mediator between the care recipient's behavioral problems and depressive symptoms of care givers. When a mediating effect of avoidance coping occurred, the care recipient's behavioral problems had no longer significance with depressive symptoms. 
Table 3

General Health Perceptions Regressed on Care Giving Variables and Coping $(\mathrm{N}=103)$

\begin{tabular}{|l|l|l|}
\hline \multicolumn{1}{|c|}{ Variable } & \multicolumn{2}{c|}{ Coping } \\
\hline Constant & Model 3a & Model 3b \\
\hline Age & 22.780 & 23.687 \\
\hline Income & $-.369^{* * *}$ & $-.414^{* * *}$ \\
\hline Care Giving Duration & .134 & .124 \\
\hline Care Recipient's Behavioral Problems & .156 & .124 \\
\hline Active Coping & $-.227^{*}$ & -.163 \\
\hline Avoidance Coping & & .047 \\
\hline Minimizing Coping & & $-.346^{* * *}$ \\
\hline Paid Assistants & & .151 \\
\hline $\mathrm{R}^{2}$ & $.267^{* *}$ & $.239^{* *}$ \\
\hline Adjusted $\mathrm{R}^{2}$ & .237 & .322 \\
\hline F Change & .198 & .264 \\
\hline
\end{tabular}

${ }^{*} p \leq .05 ; * * p \leq .01 ; * * * 0.001$

Table 4

Depressive Symptoms Regressed on Care Giving Variable and Coping $(\mathrm{N}=103)$

\begin{tabular}{|l|l|l|}
\hline \multicolumn{1}{|c|}{ Variable } & \multicolumn{2}{c|}{ Coping } \\
\hline Constant & Model 4a & Model 4b \\
\hline Age & 20.590 & 13.060 \\
\hline Income & .040 & .093 \\
\hline Care Giving Duration & $-.332^{* * *}$ & $-.336^{* * *}$ \\
\hline Care Recipient's Behavioral Problems & -.079 & -.025 \\
\hline Active Coping & $.232^{*}$ & .097 \\
\hline Avoidance Coping & & -.141 \\
\hline Minimizing Coping & & $.610^{* * *}$ \\
\hline Paid Assistants & & -.096 \\
\hline $\mathrm{R}^{2}$ & $-.285^{* *}$ & $-.220^{* *}$ \\
\hline Adjusted $\mathrm{R}^{2}$ & .236 & .510 \\
\hline F Change & .196 & .468 \\
\hline$* p<05 * * * p<.01 * * * * p<.001$ & & \\
\hline
\end{tabular}

${ }^{*} p<.05 ; * * p<.01 ; * * *<.001$

\section{Discussion}

The present findings support care giving is stressful and causes deleterious consequences for care givers. Statistical analysis of mediator and moderator testing (Baron \& Kenny, 1986), only avoidance coping had a mediating effect between care recipient's behavioral problems and depressive symptoms of care givers, with no moderating effects.
This female study had higher mean scores of depressive symptom scores $($ Mean $=28.96)$ than the mean rates from 19.7-24 in Youn and colleague's study (Youn, Knight, Jeong, \& Benton, 1999). Females were a high percentage of care givers and usually had inter-role conflicts and that may cause high levels of depression. Miller and Cafasso (1992) indicated that due to the gender role differences as a result of current 
social role demands, females usually assumed responsibilities for more tasks than males, which may cause differences in burden.

Consistently, Powers, Gallagher-Thompson, and Kraemer (2002) conducted a coping and depression in Alzheimer's care giving study, they found avoidance coping had a positive relationship with depressive symptoms. Comparing a previous study, care givers who used more active coping decreased their mental health problems (Nuendorfer, 1991).

Correlational analyses revealed older care givers had poorer health than younger care givers. The results was thus consistent with the findings of studies by Sparks et al. (1998) and Stommel et al. (1990). Care givers with higher monthly incomes had better health than those with lower incomes. No research has been done in Taiwan on the relationship between income and health outcomes of family care givers. Three studies in the US had reported a positive relationship between income and health of care givers who care for the elderly with dementia (Lawton et al., 1992; Montgomery, Stull, \& Borgatta, 1985; Schulz \& Williamson, 1991). Older care givers had less active coping than younger care givers, which is not relevant to Winslow's study (1997). In general, younger people are most active in daily life than older adults. Care givers who had higher monthly incomes also used more active coping than those with lower incomes. Adequate finance may help care givers to receive more assistance or choices.

The care giving duration is not significant with female care giver's health in this secondary data analysis study, which might be due to female care giver can adjust very well to their care giving situations. In the previous studies, care givers who had longer care giving duration had better health in Taiwan (Kao, Lu, Yen, \& Liu, 1999) and in the USA (Moen, Robinson, \& Dempester-McClain, 1995). Care givers who had paid-in-home assistants had better health than those without paid assistants. Paid assistants could decrease the family care giver's care load and their depressive symptoms. Curran (1995) has studied the benefits of paid helpers such as reduced distress, improved mood, and decreased time consumed. By using multiple regression analyses, younger care givers with paid helpers had better health.

For the main effect of coping, younger care givers who had paid helpers and less avoidance coping had better health, accounted for $26.4 \%$ in general health perceptions. Younger care giver, with paid helpers, and their care recipients with less behavioral problems explained $19.8 \%$ of variances in general health perceptions. On the other hand, care givers who used more avoidance coping had worse health, which was consistent with a previous study (Nuendorfer, 1991). Neurndorfer (1991) reported that family care givers of the elderly who used more avoidance and minimizing coping had worse health.

For the mediating effect of coping, based on the conceptual model and previous studies (Goode et al., 1998; Haley et al., 1987; Musil \& Ahmad, 2002), avoidance coping was a mediator between the care recipient's behavioral problems and depressive symptoms of care givers. When a mediator of avoidance coping occurred, the care recipient's behavioral problems had no longer significance with depressive symptoms. Inconsistently, Haley and colleagues (1996) indicated when care givers used more avoidance coping, they usually had higher depressive symptom scores. Musil and Ahmad (2002) conducted a grandmother care giving study, they found that avoidance coping had a mediating effect between care giving stress and their health outcomes. When these grandmothers had more avoidance coping, they had higher level of depression.

\section{Limitations}

Two limitations of this study include convenience sampling and the use of only two settings in the south of Taiwan may restrict the population. The generalizability was limited in the south of Taiwan. Additionally, the crosssectional nature of the present data made a difficulty to assess study variables over time.

\section{Implication for Practice}

This study indicated care giving stress had significant findings of care giver's depressive 
symptoms and general health. Nurses may assess and evaluate the factors of care giving, which could make deleterious consequence for the care giver's health. According to the results of this study, more active coping, more minimizing coping, and less avoidance coping could decrease depressive symptoms of care givers. Nurses could use effective coping strategies as interventions to help care givers of the elderly with dementia to adjust better in their care giving situations. In addition, home health care professionals need to help care givers of cognitively or physically impaired elders to recruit more care givers from the family network. Coping (active, avoidance, and minimizing) may help family care givers to decrease their negative health outcomes and to increase their well-being.

\section{References}

Anderson, G. S., Linto, J., \& Stewart-Wynne, E. G. (1995). A population based assessment of the impact and burden of care giving for long-term stroke survivors. Stroke, 26(5), 843-849.

Aneshensel, C. S., Pearlin, L. I., Mullan, J. T., Zarit, S. H., \& Whitlatch, C. (1995). Profile in care giving. San Diego, CA: Academic Press.

Baron, R. M., \& Kenny, D. A. (1986). The moderator-mediator variable distribution in social psychological research: conceptual, strategic, and statistical consideration. Journal of Personality and Social Psychology, 51(6), 1173-1182.

Beach S. R., Schulz, R., Yee, J. L., \& Jackson, S. (2000). Negative and positive health effects of caring for a disabled spouse: Longitudinal findings from the care giver health effects study. Psychology and Aging, 15(2), 259-271.

Berry, G. L., Zarit, S. H., \& Rabatin, V. X. (1991). Care giver activity on respite and non-respite days: A comparison of two service approaches. The Gerontologist, 31(6), 830-835.

Borden, W., \& Berlin, S. (1990). Gender, coping, and psychological well-being in spouses of older adults with chronic dementia. American Journal of Clinical Oncology, 13(5), 420-423.

Brody, E. M.(1981). "Women in the middle" and family help to older people. Gerontologist, 21, 471-479.

Brown, L. J., Potter, J. F., \& Foster, B. G. (1990). Care giver burden should be evaluated during geriatric assessment. Journal of the American Geriatrics Society, 38(4), 455-460.

Chiu, S. H. (1998). Using triangulation methodology study on role strain and demands on family care givers for spinal cord injury patients during discharge transition. Nursing Research, 6(6), 513525. (In Chinese).

Chou, K. R., LaMontagne, L. L., \& Hepworth, J. T. (1999). Burden experience by care givers of relatives with dementia in Taiwan. Nursing Research, 48(4), 206-214.

Cares National Association (CNA). (1997). General election briefing 1997. The Carer (Suppl.), March, CNA, 20/25 Glashouse Yard, London, EC1A 4JS, England.

Crassel, E. (1998). Home care of demented and non-demented patients: Health and burden of care givers. Journal of Gerontology Geriatrics, 31(1), 57-62.

Curran, J. M. (1995). Current provision and effectiveness of day care services for people with dementia. Reviews in Clinical Gerontology, 5(3), 313-320.

Folkman, S., Lazarus, R. S., Dunkel-Schetter, C., DeLongis, A., \& Gruen, R. (1986). The dynamics of a stressful encounter: Cognitive appraisal, coping, and encounter outcomes. Journal of Personality and Social Psychology, 50, 992-1003.

Folkman, S., Lazarus, R. S., Pimley, S., \& Novacek, J. (1987). Age difference in stress and coping processes. Psychology and Aging, 2(2), 172-184.

Given, C. W., Collins, C. E., \& Given, B. A. (1988). Sources of stress among families caring for relatives with Alzheimer disease. Nursing Clinics of North American, 23(1), 69-82.

Gallicchio, L., Siddiqi, N., Langenberg, P., \& Baumgarten, M. (2002). Gender difference in burden and depression among informal caregivers of demented elders in the community. International Journal of Geriatric Psychiatry, 17(2), 154-163. 
Gonzalez-Salvador, T., Arango, C., Lyketsos, C. G., \& Barba, A. C. (1999). The stress and psychological morbidity of Alzheimer's patient care giver. International Journal of Geriatric Psychiatry, 14, 701-710.

Goode, K., Haley, W., Roth, D., \& Ford, G. (1998). Predicting longitudinal changes in care giver physical and mental health: A stress process model. Health Psychology, 17(2), 190-198.

Haley, W. E., Levine, E. G., Brown, S. L., \& Bartolucci, A. A. (1987). Stress, appraisal, coping, and social support as predictors of adaptational outcome among dementia care givers. Psychology and Aging, 2, 323-330.

Haley, W. E.; Roth, D. I., Coleton, M. I., Ford, G. R., West, C. A. C., Collins, R. P., \& Isobe, T. L. (1996). Appraisal, coping, and social support as mediators of well-being in black and white family care givers of patients with family care givers of patients with Alzheimer's disease. Journal of Consulting and Clinical Psychology, 64(1), 121-129.

Huang, C. Y., \& Musil, C. M. (2003). Effects of social support and coping of primary family care givers of elders with dementia in Taiwan. (Non-published).

Hung, L. C., Liu, C. C., Kuo, H. W., Hwang, M. N., Chang, L. W., \& Lin, J. J. (1999). Effectiveness of Nursing Instructions given to care givers of Long-term bedridden patients. Nursing Research, 7, 363-375. (In Chinese).

Kao, S. F., Lu, Z. Y., Yen, S. H., \& Liu, H. E. (1999). The relationship between family function, social support, and care giver burden for dependent elderly. Nursing Research, 7, 172-182.

Kiecolt-Glaser, J. K., Marucha, P. T., Malarkey, W. B., Mercado, A. M., \& Glaser, R. (1995). Slowing of wound healing by psychological stress. Lancet, 346, 1194-6.

Krongrad, A., Perczek, R. E., Burke M. A., Granville, L. J., Lai, H., \& Lai, S. (1997). Reliability of Spanish translations of select urological quality of life instruments. Journal of Urology, 58:493-6.

Lawton, M. P., Rajagopal, D., Brody, E., \& Kleban, M. H. (1992). The dynamics of care giving for demented elder among black and white families. Journal of Gerontology, 47 (Suppl.), S156-S164.

Linn, N., Dean, A., \& Ensal, W. (1986). Social support, life events, and depression. New York: Academic Press.

Lyu, S. U., \& Lin, T. Y. (2000). Prevalence and correlates of depressive symptoms among communitydwelling elderly in southern Taiwan. Chinese Journal of Public Health, 19(1), 50-60.

McHorney, C. A., Ware, J. E. Jr., \& Raczek, A. E. (1993). The MOS 36-item short-form health survey (SF-36): II. Psychometric and clinical tests of validity in measuring physical and mental health constructs. Medical Care, 31, 247-63.

Miller B, \& Cafasso, L. (1992). Gender differences in care giving: fact or artifact? Gerontologist, 32(4), 498-507.

Moen, P., Robinson, J., \& Dempster-McClain, D. (1995). Care giving and women's well-being : A life course approach. Journal of Health and Social Behavior, 36, 259-273.

Montgomery, R. J. V., \& Borgatta, E. F. (1989). The effects of alternative support strategies on family care giving. The Gerontologist, 29, 457-464.

Montgomery, R. J. V. (1995). Examining respite care: Promises and limitations. In R. A. Kane, \& J. D. Penrod (Eds.), Family care giving in an aging society. (pp. 22-45). London: Sage Publications.

Musil, C. M., \& Ahmad, M. (2002). Health of grandmother: A comparison by care giver status. Journal of Aging and Health, 14(1), 96-121.

Nerenz, D. R., Repasky, D. P., Whitehouse, F. W., \& Kahkonen, D. M. (1992). Ongoing assessment of health status in patients with diabetes mellitus. Medical Care, 30 (5 Suppl.), MS112-24.

Neundorfer, M. (1991). Coping and health outcomes in spouse care givers of persons with dementia. Nursing Research, 40, 5, 260-264.

Niederehe, G., \& Fruge, E. (1984). Dementia and family dynamics: Clinical research issues. Journal of Geriatric Psychiatry, 17(1), 21-60.

Ory, M. G., Hoffman, R. R., Yee, J. L., Tennstedt, S., \& Schulz, R. (1999). Prevalence and impact of care giving: A detailed comparison between dementia and non-dementia care givers. Gerontologist, $39,177-185$. 
Parks, S. H., \& Pilisuk, M. (1991). Care giver burden: Gender and psychological costs of care giving. American Journal of Orthopsychiatry, 61, 501-509.

Pearlin, L. I., Turner, H., \& Semple, S. (1989). Coping and the mediation of care giver stress. In E. Light $\&$ B. D. Lebowitz, Alzheimer's disease treatment and family stress: Directions for research. Rockville, MD: US Department of Health \& Human Services.

Powers, D. V., Gallagher-Thompson, D., \& Kraemer, H. C. (2002). Coping and depression in Alzheimer's care giver: Longitudinal evidence of stability. Journal of Gerontology: Social Science, 57, 205-211.

Pruchno, R. A., \& Potashnik, S. L. (1989). Care giving spouses physical and mental health in perspective. Journal of Geriatrics Society, 37, 697-705.

Radloff, L. S. (1977). The CES-D scale: A self-report depression scale for research in the general population. Applied Psychological Measurement, 4, 454-463.

Sayles-Cross, S. (1993). Perceptions of familial care givers of elder adults. IMAGE: Journal of Nursing Scholarship, 25(2), 88-92.

Schindler, R. J., \& Cucio, L. P. (2000). Late-life dementia: Review of the APA guidelines for patients management. Geriatrics, 55, 55-60.

Schulz, R., Newsom, J. T., Mittelmark, M., Burton, L., Hirsch, C., \& Jackson, S. (1997). Health effects of care giving: The cardiovascular health study. Annals of Behavioral Medicine, 19, 110-116.

Schulz, R., O’Brien, A., Bookwala, M. S., \& Fleissner, K. (1995). Psychiatric physical morbidity effects of dementia care giving: Prevalence, correlates, and causes. The Gerontologist, 35, 771-791.

Schulz, R., \& Williamson, G. M. (1991). A 2-year longitudinal study of depression among Alzheimer's care givers. Psychology and Aging, 6, 569-578.

Shields, C. G. (1992). Family interaction and care givers of Alzheimer's disease patients: Correlates of depression. Family Process, 31, 19-33.

Smyth, K., \& Yarandi, H. N. (1996). Factor analysis of the ways of coping questionnaire for African American women. Nursing Research, 45(1), 25-29.

Sparks, M. B., Donner, E., \& Keane-Hagerty, E. (1998). Wives, husbands, and daughters of dementia patients: Predictors of care givers' mental and physical. Scholarly Inquiry_Nursing Practice: An International Journal, 12, 221-234.

Stommel, M., Given, C. W., \& Given, B. (1990). Depression as an overriding variable explaining care giver burden. Journal of Aging and Health, 2, 81-102.

Stone, R., Cafferata, G. L., \& Sangl, J. (1987). Care givers of the frail elderly: A national profile. The Gerontologist, 27, 616-626.

Thoit, P. A. (1994). Stressors and problem-solving: The individual as psychological activist. Journal of Health and Social Behavior, 35, 143-160.

Walker, A., Martin, S., \& Jones, L. (1992). The benefits and costs of care giving and care receiving for daughters and mothers. Journal of Gerontology, 47(3), S130-139.

Ware, J. E., Jr. (1990). SF-36 health survey update. Spine 2000, 25, 3130-3139.

Ware, J., Kosinski, M., Bayless, M., McHorney, C., Rogers, W., \& Raczek, A. (1995). Comparison of methods for the scoring and statistical analysis of SF-36 health profile and summary measurements: Summary of results from the medical outcomes study. Medical Care, 30, MS253MS265.

Ware, J. E., Jr., \& Sherborne, C. D. (1992). The MOS 36-item short-form health survey (SF-36). Conceptual framework and item selection. Medical Care, 30, 473-483.

Whitlatch, C. J., Feinberg, L. F., \& Sebesta, D. S. (1997). Depression and health in family care giversadaptation over time. Journal of Aging and Health, 9, 222-243.

Winslow, B. T. (1997). Effects of formal support on stress outcomes in family care givers of Alzheimer's patients. Research in Nursing \& Health, 20, 27-37.

Wright, L. K., Clipp, E. C., \& George, L. K. (1993). Heath consequences of care giver stress. Medicine, Exercise, Nutrition, and Health, 2, 181-195. 
Wright, L.K. Hickey, J.V., Buckwalter, K.C., Hendrix, S. A., \& Kelechi,T. (1999). Emotional and physical health of spouse care givers of persons with Alzheimer's disease and stroke. Journal of Advanced Nursing, 30, 552-563.

Yee, J.L., \& Schultz, R. (2000). Gender differences in psychiatric morbility among family care givers: a review and analysis. Gerontologist, 40(2), 147-164.

Youn, G, Jeong, H. S., Knight, B. G., \& Benton, D. (1999). Differenced in familism values and care giving outcomes among Korean, Korean American, and white American dementia care givers. Psychology and Aging, 14, 355-364.

Zanetti, O., Frisoni, G. B., Bianchetti, A., Tamanza, G., Cigoli, V., \& Trabucchi, M. (1998). Depressive symptoms of Alzheimer's care givers are mainly due to personal rather than patient factors. International Journal of Geriatric Psychiatry, 13(6), 358-367.

\author{
Author Information \\ Chiung-Yu Huang, Ph.D., RN \\ Nursing Department \\ MeiHo Institute of Technology \\ Taiwan \\ E-Mail: x2079@meiho.edu.tw
}

